\title{
Towards post-multiculturalism? Changing communities, conditions and contexts of diversity*
}

\author{
Steven Vertovec
}

For more than 30 years across a range of countries, numerous policies have had as their overall goal the promotion of tolerance and respect for group identities, particularly of immigrants and ethnic minorities. Collectively called multiculturalism, these policies have been pursued through measures such as supporting community associations and their cultural activities, monitoring diversity in the workplace, encouraging positive images in the media and modifying public services in order to accommodate culture-based differences of value, language and social practice.

By the early part of the twenty-first century multiculturalism has been seriously challenged from a number of directions. The changing nature of global migration, new social formations spanning nation-states and the persistently poor socioeconomic standing of immigrant and ethnic minority groups are among the foremost developments that seem to render obsolete the older models of multiculturalism. In light of and added to these conditions, there has emerged in public discourse across numerous settings - especially in Europe a broad backlash against multiculturalism (see Vertovec and Wessendorf 2010). From the political Right many critics now see multiculturalism as a foremost contributor to social breakdown, ethnic

${ }^{*}$ This article is reprinted from International Social Science Journal, 2010; 61: 83-95 tension and the growth of extremism and terrorism. From the Left, where numerous commentators were long dubious of a seeming complicity with Empire and willing blindness to class-based inequalities, even previous supporters of multiculturalism came to question the model as contributing to a demise of the welfare state and the failure of public services.

For all these reasons there are widespread calls to rethink multiculturalism. This article describes changing contexts surrounding multiculturalism and discusses whether, as some suggest, we are shifting into a post-multiculturalist world. It also addresses, in passing, several other pertinent questions today, including: what are the changing public discourses surrounding multiculturalism? What are the characteristics of new forms of immigration? How have these new forms of immigration impacted on multicultural theories? What are the relationships of immigrants with sending countries? How do all of these patterns contribute to what might be called postmulticulturalism?

Following an initial section outlining some key aspects of conventional multiculturalism and its critiques, the article includes sections describing emergent migration trends leading toward conditions of "super-diversity", patterns of diasporic identification and transnationalism, recent public debates that are critical of multiculturalism and various policy measures taken in response. It 
concludes with speculations on the emergence of post-multicultural perspectives that seek to foster both the recognition of diversity and the maintenance of collective national identities.

\section{Multiculturalism}

Looking back historically and considering cases in contexts such as the colonial period, the Ottoman Empire and the Roman Empire, we can observe that in populations composed of linguistically, culturally and religiously heterogeneous groups there have always been questions of multi-group governance and negotiation surrounding everyday practices and interactions. Aspects of diversity had to be managed in order to ensure the nonalienation of specific groups (at least to ensure rule or policy delivery), the limitation of conflict (at least in ways that did not hurt the dominant group), and the generally smooth functioning of society (or at least the economy). The great age of migration from Europe to the western hemisphere in the latter half of the nineteenth century brought some relatively new issues of diversity management to immigrant-receiving countries, but expectations of assimilation - or publicly discarding social and cultural difference - largely held sway. In the last half of the twentieth century, particularly in the wake of successful civil rights movements that demanded public measures to mitigate discrimination, social, political and public service challenges arose stemming from yet newer waves of largescale immigration and the settlement of sizable communities. These challenges prompted many nation-states, their local government institutions, and many businesses, and public and voluntary sector organisations to adopt policies, structures and programmes designed to address newly emergent modes of diversity and their accommodation in wider society.

\section{The paradigm of multiculturalism}

Collectively described as multiculturalism, these late twentieth-century institutional initiatives had a number of broad, common objectives. These included providing opportunities for group representation to local and national government authorities; restructuring institutions towards pluralistic public service provision; putting in place measures to promote equality, respect or tolerance, particularly among the dominant population towards minorities; and providing resources to support the continuity of traditions and identities among immigrant groups (as opposed to assimilation). Further, in many countries multiculturalism differentially entailed actions in the following fields:

- public recognition: supporting ethnic minority organisations, facilities and activities and creating public consultative bodies incorporating such organisations

- education: often addressing dress, gender and other issues sensitive to the values of specific ethnic and religious minorities; creating curricula reflecting the backgrounds of ethnic minority pupils; offering mother tongue teaching and language support and establishing own schools (publicly financed or not)

- culturally sensitive practices, training and information established within social services and among healthcare providers, police and the law courts

- public materials: providing public material (such as health promotion campaigns) in multiple languages

- law: recognising cultural exceptions to laws (such as Sikh turbans instead of motorcycle helmets); permitting oaths on sacred books other than the Bible; recognising other marriage, divorce and inheritance traditions; protecting cultural practices from discrimination and incitement to hatred

- religious accommodation: permitting and supporting the establishment of places of worship, cemeteries and funerary rites; allowing time off work for worship

- food: allowing ritual slaughter; providing proscribed foods (halal, kosher, vegetarian) in public institutions

- broadcasting and media: monitoring group images to ensure non-discrimination or to avoid stereotypes; providing own media facilities for minority groups.

To be sure, the policy and programmatic elements of multiculturalism have not been the same in its primary countries of general implementation (particularly Australia, Canada, the USA, the UK, Sweden and The Netherlands). Even within the same country, policies relevant to an overall 
multiculturalist agenda have not used the same perspectives, or had the same aims and approaches. Similarly, public discourse (as found in political debates, media treatment and public opinion polls) has comprised a variety of takes on the topic. Hence, as Stuart Hall (2001, p.3) observes:

Over the years the term "multiculturalism" has come to reference a diffuse, indeed maddeningly spongy and imprecise, discursive field: a train of false trails and misleading universals. Its references are a wild variety of political strategies. Thus conservative multiculturalism assimilates difference into the customs of the majority. Liberal multiculturalism subordinates difference to the claims of a universal citizenship. Pluralist multiculturalism corrals difference within a communally segmented social order. Commercial multiculturalism exploits and consumes difference in the spectacle of the exotic "other." Corporate multiculturalism manages difference in the interests of the centre.

Others have pointed to the ideas and programmes surrounding "radical multiculturalism" or "polycentric multiculturalism" (Shohat and Stam 1994), “insurgent multiculturalism"' (Giroux 1994), “public space multiculturalism", (Vertovec 1996), "difference multiculturalism" (Turner 1993) and "critical multiculturalism" (Turner 1993; Chicago Cultural Studies Group 1994). Similarly Gerard Delanty (2003) describes nine kinds of multiculturalism while Vertovec (1998) has pointed to at least eight different takes on multiculturalism.

The creation and implementation of multicultural policies, structures and programmes have, according to a range of critics in academia, politics and the media, entailed a number of problems. Some commentators have pointed to the ways in which multiculturalism contributes to the marginalisation of minorities by keeping them off serious government policy agendas; others suggest multiculturalism comprises a divide-and-rule strategy by government in relation to ethnic minorities, wrought by ethnic minority associations' competition for funding or political influence. Still others point to the misleading, tokenist and reifying view of communities as never-changing, socially bounded entities, which is inherent in multicultural ideology. And there are many who have criticised multiculturalism's overemphasis on the maintenance of culture at the cost of paying less policy attention to socioeconomic deprivation.

Despite these and more recent criticisms (see below), in most places multiculturalism has been successfully mainstreamed in the public sphere, such that pluralistic provisions and some acceptance of the need to be culturally sensitive (ridiculed as "political correctness") have become widespread and commonplace. The following book titles from the late 1980s-1990s, when multiculturalism, by this name, reached its peak, attest to the variety of public domains reached by the concept: Medical practice in a multicultural society (1988), Counselling and psychotherapy: a multicultural perspective (1993), Managing substance abuse in a multicultural society (1994), Marketing in a multicultural world (1995), Multiculturalism: criminal law (1991), and Multicultural public relations (1995). By the end of the century multiculturalism was to be found everywhere in public discourse, policy and practice, consequently leading the renowned sociologist Nathan Glazer (1997) to observe, "We are all multiculturalists now".

\section{The turn against multiculturalism}

Although since the 1960s there have always been critical views of multiculturalism - seen in various ways as pandering to immigrants and ethnic minorities - by the late 1990 s and early 2000 s very serious questions arose as to the effectiveness and worth of multicultural policies.

Despite mainstreaming, the growth of respect and tolerance for minorities seemed limited: evidence of the persistence of discrimination and racism was rife, and Europe, Australia, Canada and elsewhere witnessed a seeming rise of rightwing extremism and success among populist, antiimmigrant political parties. Census and other social surveys in numerous countries indicated deep and enduring patterns of inequality among ethnic minorities (by now in their second or third generation after the original immigrants): low educational attainment, high unemployment, poor jobs, low income, bad quality housing, ill health and little social mobility. In the UK, Germany and elsewhere, reports suggested that natives and immigrants or ethnic minorities were living parallel lives marked by residential segregation, effectively separate schools, different places of worship, divergent community associations, discrete social networks and disparate places of leisure. Policymakers feared that such seeming separateness might provide a breeding ground for extremism; and the fact that the 2005 London bombers were home 
grown terrorists, born and raised in the UK, seemed to exemplify this.

In many, if not all, western countries of immigration, a remarkably common public discourse emerged: there had been a "failure of integration" and multiculturalism was largely to blame. Surely multicultural policies should have delivered something different? Less success for the far Right, more socioeconomic mobility for minorities, a better sense of belonging to the wider society?

From the political Right most of the preexisting criticisms were voiced anew: multiculturalism, they said, keeps ethnic minorities distinct and breaks down common values and national identity. Yet new criticisms began to be heard from the political Left: multiculturalism, some said, broke down people's sense of mutual obligations and willingness to contribute to the welfare state. Linking all such discourse was the assumed logic that (a) multiculturalism fosters accentuated or preserved cultural differences; (b) such differences lead to communal separateness; (c) separateness, in turn, entails the lack of socioeconomic mobility, the breakdown of social relations, grounds for conflict and a potential for extremism, even terrorism. Also present in such discourse or logic, the criticism of multiculturalism also entails the criticism of immigrants and ethnic minorities themselves. As this thinking goes, it is their own desire to maintain cultural traditions and distinct identities - a desire that multiculturalism supports - that leads to all these negative consequences. Meanwhile, a variety of structural conditions, institutional obstacles or policy failures compound the reproduction of the poor socioeconomic status of immigrants and ethnic minorities. (While expert analysts are able to account for such an array of factors, the popular media and many politicians often have neither the time nor the interest in exploring the complex processes and causalities that underlie forms of inequality).

In these ways across several different national sites, emergent social conditions, prominent events and reactive public discourses have combined to a paint a rather disapproving, if not outright damaging picture (albeit a fairly caricatured one) of multiculturalism. Added to this important trend, recent patterns of global migration and certain practices developing among migrants themselves also present factors that contribute to the need to rethink certain aspects of multiculturalism as well.

\section{"Super-diversity"}

In the twentieth century, post-war migration primarily consisted of substantial numbers moving internationally by way of specific recruitment or other regulated schemes to supply low or semiskilled labour. In most places, reaching a zenith in the 1960s, these notably included migration from particular sites in Turkey to Germany, from Algeria to France, from Mexico to the USA and from Pakistan to the UK. As families joined and expanded the immigrant worker population into the 1970s, explicit or implicit multicultural policies and structures accordingly arose to engage what were becoming large, increasingly well-organised and settled communities.

Today the scene is considerably different. There has been a worldwide rise in migrant (including refugee) numbers over the past two decades: up to some 214 million at present. Furthermore - and significantly - more people are now moving from more places, through more places, to more places.

In comparison with the large immigrant groups that were representative of the 1950-1970s migrations, today newer, smaller, transient, more socially stratified, less organised and more legally differentiated immigrant groups comprise global migration flows. Such complex social formations have attracted little attention or a place on the public agenda, which is still largely based on models of previous migration flows. Yet it is the growth of exactly these new varieties of migrants that has in recent years radically transformed the social landscape of migrant-receiving countries. The time has come to re-evaluate - in social scientific study as well as policy - the nature of contemporary diversity (see Vertovec 2009a). With a reworked understanding of new complexities of diversity, the structures and policies meant to deal with diversity - that is, multiculturalism - need to be reworked too.

\section{The emergence of super-diversity}

In order to better understand and more fully address the complex nature of contemporary, migrationdriven diversity, additional variables need to be taken into account by social scientists, policymakers, practitioners and the public. The interplay of these factors is what is meant by the notion of "super-diversity" (Vertovec 2007). 
Super-diversity is a term intended to capture a level and kind of complexity surpassing anything many migrant-receiving countries have previously experienced. Immigrant superdiversity is distinguished by a dynamic interplay of variables, including their country of origin (comprising a variety of possible subset traits such as ethnicity, language[s], religious tradition, regional and local identities, cultural values and practices), their migration channel (often related to highly gendered flows, specific social networks and particular labour market niches), and their legal status (including myriad categories determining a hierarchy of entitlements and restrictions). These variables co-condition integration outcomes along with factors surrounding migrants' human capital (particularly their educational background), access to employment (which may or may not be in the immigrants' own hands), locality (related especially to its material conditions, but also to the presence of other immigrant and ethnic minorities) and the usually chequered responses by local authorities, services providers and local residents (which often tend to function by way of assumptions based on previous experiences with migrants and ethnic minorities).

\section{British super-diversity as exemplar}

The British case, presented below, presented below, is representative of diversification processes, trends and characteristics recently arising in many immigrant receiving countries.

Countries of origin. One of the most noteworthy features of the new migration is the multiplicity of immigrants' countries of origin. Moreover, most of this new and diverse range of origins relates to places that have no specific historical - particularly, colonial - links with the UK. In London alone there are people from some 179 countries. In many cases there are just a handful of people from a country, but there are groups numbering over 10,000 individuals from each of no fewer than 42 countries, respectively, and there are over 5,000 individuals from a further 12 countries. While country of origin data provide important indicators of diversity, they may mask more significant forms of differentiation than they reveal. Within any particular group from a given country there will be important distinctions in ethnicity, religious affiliation and practice, regional and local identities in the migrants' place of origin, kinship, clan or tribal affiliation, political parties and movements, and other criteria of collective belonging.

Languages. The growth of multilingualism in the UK has been recognised and engaged in in various ways by both social scientists and policymakers, although the latter have often arguably failed to respond in positive or adequate ways. Multilingualism is routinely viewed with suspicion or derision, and there is much criticism against the use of public money to provide widespread translation services. Still, it is now often proclaimed with pride (for instance, in the city's successful 2012 Olympic bid) that 300 languages are spoken in London.

Religions. On the whole, we can say that among immigrants to the UK, Christianity is the main religion for people born in all continents except Asia. Asia-born people in the UK are more likely to be Muslim than any other religion, although Indians include a majority of Hindus and a significant number of Sikhs. For many, religions tend to be broadly in line with countries of origin - Irish and Jamaicans are mostly Christian, Bangladeshis mostly Muslim and so forth - but even so these categories often miss important variations in devotional traditions in each of the world religions. Taking Islam as example, it is often pointed out that there are several traditions within the faith as practiced by South Asians in the UK (Deobandi, Tablighi, Barelvi, Sufi orders and more). Such variations are multiplied many times when we consider the breadth of origin among Muslims from around the world who now live in the UK (such as Nigerians, Somalis, Bosnians, Afghans, Iraqis and Malaysians). In London Muslims are the most heterogeneous body of believers in terms of ethnicity and country of origin, with the largest group (Bangladeshis) making up only 23.5 per cent. 'London's Muslim population of 607,083 people is probably the most diverse anywhere in the world, besides Mecca"' (The Guardian 2005).

Migration channels and immigration statuses. Sociocultural axes of differentiation, such as country of origin, ethnicity, language and religion are significant in conditioning immigrants' identities, patterns of interaction and - often through social networks determined by such axes - their access to jobs, housing, services and more. However, the channels of migration and the myriad legal statuses that arise from them are often just as, or even 
more crucial to the way in which people group themselves and where they live, how long they can stay, how much autonomy they have (versus control by an employer, for instance), whether their families can join them, what kind of livelihood they can undertake and maintain and to what extent they can make use of public services and resources (including schools, health, training, benefits and similar "recourse to public funds"). Therefore such channels and statuses, along with the rights and restrictions attached to them, comprise an additional - indeed, fundamental - dimension of today's patterns and dynamics of superdiversity.

Coinciding with the increasing influx of immigrants to the UK in the 1990s there has been an expansion in the number and kind of their migration channels and immigration statuses. Each carries quite specific and legally enforceable entitlements, controls, conditions and limitations. The most prominent are the following channels and statuses:

- Workers. Between 1993 and 2003 the number of foreign workers in the UK rose no less than 62 per cent to $1,396,000$. This largescale increase in workers includes people who have come under numerous categories and quota systems.

- Students. The number of foreign students entering the UK peaked at 369,000 in 2002 before being reduced to 319,000 in 2003. Non-EU students accounted for some 38 per cent of all full-time higher degree students in 2003.

- Spouses and family members. The number of migrating spouses and family members coming to the UK more than doubled between 1993 and 2003. Furthermore, this is a particularly feminised channel of migration compared with others;

- Asylum-seekers and refugees. Throughout the 1990s the number of asylum applications rose considerably in the UK and indeed throughout Europe. Applications (including dependents) in the UK rose from 28,000 in 1993 to a peak of 103,100 in 2002 . This, too, is a highly gendered channel of migration: in 2003 some 69 per cent were male. The provenance of asylum-seekers represents a broad range: in 2003 applications were received from persons spanning over 50 nationalities.

- Irregular, illegal or undocumented migrants. This category, variously termed, pertains to people whose presence is marked by clandestine entry, entry by deceit, overstaying or breaking the terms of a visa. In 2005 the Home Office offered a best guess number of between 310,000 and 570,000 irregular migrants in the UK.

- New citizens. A great many migrants become full citizens. During the 1990s around 40,000 people became citizens each year. This number has risen dramatically since 2000, with 2004 seeing a record number of 140,795 granted British citizenship. In attempting to understand the nature and dynamics of diversity in the UK, close attention must be paid to the stratified system of rights, opportunities, constraints and partial-to-full memberships that coincide with these and other immigrant categories.

Moreover - and denoting a key feature of superdiversity - there may be widely differing statuses within groups of the same ethnic or national origin.

These facts underscore the point that simple ethnicity-focused approaches to understanding and engaging various minority "communities" in Britain, as taken in many models and policies in conventional multiculturalism, are inadequate and often inappropriate for dealing with individual immigrants' needs or understanding the dynamics of their inclusion or exclusion.

Gender. Over the past 30 years, more women than men migrated to the UK. Since about 1998, men have come to dominate in new flows. The reason for this may be due to a general shift away from more female-oriented family migration to more male-dominated work-based migration schemes since 1995 . It is also likely to be related to the inflow of asylumseekers, most of whom have been male.

Age. The new immigrant population has a higher concentration of 25-44-year-olds and a lower proportion of under-16s than a decade ago, also perhaps reflecting a shift away from family migration. Variance in age structure among various ethnic groups reflects different patterns of fertility and mortality as well as migration. The mean age of new immigrants is 28 , averaging 11 years younger than the mean age of 39 for the UK-born population.

At both national and local levels policymakers and public officers continuously face the task of refashioning their tools in order to be most effective in light of changing circumstances (whether these are socioeconomic, budgetary or set by government 
strategy). This is equally the case for policies for community cohesion, integration, managed migration and managed settlement. Structures and modes of government support for, and liaison with, ethnic minority organisations have for decades formed the backbone of the British model of multiculturalism. Especially at local levels, these have indeed often provided important forums for sharing experiences and needs, establishing good practices and providing access to services. However, in light of the numerous dimensions of superdiversity, such structures and modes are inadequate for effective representation. Most local authorities have been used to liaising with a limited number of large and well-organised associations; now there are far more numbers in groups that are smaller and less well organised or completely unorganised. In any case, just how many groups could such structures support? And how should local authorities deal with the internal diversity of various groups, not least in terms of their legal status?

Already, existing minority ethnic agencies often cannot respond to the needs of the various newcomers. None of this is to say that community organisations no longer have a place in bridging migrant groups and local authorities or service providers. Such bodies remain crucial to the process but they should be recognised as only partially relevant with regard to their representativeness and scope.

The growing size and complexity of the immigrant population carries with it a range of significant public service implications. Executives in local authorities around the UK have voiced concerns about the ability of transport systems, schools and health services to manage new needs. Such concerns flag the need for a substantial shift in strategies across a range of service sectors concerning the assessment of needs, planning, budgeting, commissioning of services, identification of partners for collaboration and gaining a broader appreciation of diverse experiences in order generally to inform debate. Such a shift must begin with gathering basic information on the new diversity.

\section{Transnationalism}

It is now widely recognised among academics and policy-makers alike that transnationalism, or the cross-border and homeland links maintained by migrants, is an inescapable fact of migration under contemporary conditions of globalisation. Advanced technologies and lower costs surrounding travel and mobility, telephone calls, Internet connectivity and satellite television have meant that dispersed groups can, with relative ease, stay in close daily contact with each other or with events in their homelands and other diasporic locations. Regular and routine transnational practices of exchange (of people, money, resources and information) and mobilisation (for business, religious, social or political purposes) in diasporic networks often ensure that common collective identities are maintained and enhanced. Also, over 25 years of multicultural policies in western migrant-receiving countries have meant that it has been widely acceptable for immigrants and their descendants to sustain culturally distinct practices and diasporic identities.

What are the implications of sustained transnational connections for integrating migrants? Various answers have been given to this question, various modes of transnationalism and integration have been examined, and various studies have attempted to measure or interrogate related processes and phenomena.

Perhaps throughout history, and certainly over the last hundred years or more, immigrants have stayed in contact with their families, organisations and communities in their places of origin and elsewhere in the diaspora. In recent years, the extent and degree of transnational engagement have intensified among immigrants due in large part to changing technologies and reduced telecommunication and travel costs. Enhanced transnationalism is substantially transforming several social, political and economic structures and practices among migrant communities worldwide in both places of migrant origin and reception.

Of course, not all migrants maintain the same desire for and levels or kinds of transnational engagement, socially, culturally, economically or politically. Much of this is largely conditioned by a range of factors including the migration channel they have taken and their legal status (for example, refugees or people without documents may find it harder to maintain certain ties abroad), their migration and settlement history, their community structure and the gendered patterns of contact, as well as the political circumstances in their homeland, their economic means and more. That is, transnational practices among immigrants are highly diverse between and within groups (whether defined by 
country of origin, ethnicity, immigration category or any other criteria), adding yet another significant layer of superdiversity to all those outlined above.

Many migrants develop and maintain strong modes of community cohesion, but not necessarily with others in their locality of settlement. The strongest senses of cohesion or belonging may remain with others in their homeland or elsewhere. However, this need not mean they are not becoming integrated in their new setting. Belonging, loyalty and sense of attachment are not parts of a zerosum game based on a single place. That is, it is not automatically true that the more transnational individuals are the less integrated they are, or that the less integrated they are the stronger their transnational patterns of association.

Empirical research has demonstrated the complex relationships between modes of transnationalism and integration (such as Morawska 2003; Smith 2006; Snel et al. 2006; Vertovec 2009b). Numerous findings, analysed and published by a variety of academics, have demonstrated that across a range of variables and correlations, modes of transnational participation have complex and generally positive relationships with processes of integration.

The incontestable fact is that with regard to both transnationalism and integration, migrants adapt. Sustained and intensive patterns of transnational communication, affiliation and exchange can profoundly affect the manner of migrant adaptation - including practices associated with positive or limited integration - through the maintenance of a particularly strong sense of connection or orientation to the people, places and senses of belonging associated with the place of origin. Such increasing incidence among contemporary migrants (especially that afforded by cheap telephone calls and transportation) arguably contributes to a more widespread process of transformation affecting many western societies, namely, the public recognition of multiple identities. As in earlier eras, migrants feel powerfully bound to homelands and communities elsewhere and now they can variously express and enhance this attachment. At the same time, new immigrants clearly are getting on with developing a new life, livelihood, social ties and political interests in their places of settlement.

Quite clearly, in the security-gripped era since 9/11, diasporic identities and transnational relations have come to be regarded by many with suspicion. There have been growing fears of ideological fifth columns, terrorist sleeper-cells and other enemies within. And regardless of the social scientific findings that migrant transnationalism does not impede integration, politicians and the wider public perceive that the maintenance of ties with homelands means that migrants and ethnic minorities have not - and do not want to - become part of their societies of settlement. Such a view, combined with the antimulticulturalism trends and the new challenges brought about by immigrant superdiversity, has arguably propelled us all into an era of postmulticulturalism.

\section{Post-multiculturalism?}

As we have seen, for a variety of reasons multiculturalism is regarded by many as a concept or set of policies that legitimised a retreat into culturally and physically separate minority communities. Rightly or wrongly, the term has become associated with socially disintegrative effects. The practice has been perceived as supporting the assumed unwillingness of migrants to integrate. In response to these issues and as a kind of corrective set of measures, policies to foster community cohesion, a stronger national identity and mandatory immigrant integration are being rolled out in countries around the world.

In countries such as France, Germany, the UK, The Netherlands, Singapore and Australia, the government has established policies and programmes implementing citizenship courses and tests for immigrants. These require the acquisition of knowledge of national civics and dominant cultural norms and values. Eligible immigrants who pass these courses and tests are rewarded with citizenship ceremonies, which are themselves meant to serve symbolically as emblems of national belonging.

Increasing language requirements for immigrants are being rolled out in many places, too. Newcomers must demonstrate acceptable standards or levels of competency in the official language, again through compulsory courses and tests, sometimes even prior to enter the country. Failure to pass such language requirements is being met by a variety of penalties.

In these ways and more, the onus and obligation is being placed on immigrants and ethnic minorities to take up the values and cultural practices of the host country and to actively demonstrate their desire to belong. Immigrants themselves tend to welcome language learning (given that low-cost 
courses are available) and generally seem willing to participate in integration courses. Such measures are seen by policy-makers as crucial steps to secure the socioeconomic mobility of immigrants and ethnic minorities, to avoid unrest and to guarantee the security of all. While it has been demonstrated that improved language skills lead to better job prospects (Dustmann and Fabbri 2003), it remains to be seen exactly how other compulsory courses and tests on the history and values of the host country will foster mobility.

These measures comprise key elements of what might be called post-multiculturalism. But this does not simply mean the return to assimilation (at least, not as it was practiced in the first half of the twentieth century). That is, despite a strong emphasis on conformity, cohesion, national identity and dominant cultural values, in practically all the contexts in which such new policies are being implemented an acceptance of the significance and value of diversity is voiced and institutionally embedded. Across the public sector and increasingly in the business world, diversity is a key term with regard to recruitment, management and equal treatment. In this way, post-multiculturalist policies and discourse seek to have it both ways: a strong common identity and values coupled with the recognition of cultural differences (alongside differences based on gender, sexuality, age and disability). As Desmond King (2005, p.122) has stated, in the USA

Modern American nationhood is an ideology of " postmulticulturalism": a wide acknowledgment of group distinctions combined with a state struggle to ensure that government policies do not accentuate hierarchical divisions between groups based on race, ethnicity and national background.... It is post- in that the demands commonly advanced under a multiculturalist agenda are now quite modest ones.

Accordingly, governments in several countries are currently challenged by a search for postmulticulturalist models that somehow fuse agendas of the left ("celebrating" diversity, fostering social capital, reducing socioeconomic inequality) and the right (promoting national identity, marginalising or eliminating competing values, limiting new immigration as a presumed inherently divisive process). As King (2005, p.123) puts it, the challenge is to construct a state ideology, structures and programmes that are "broad enough to permit strong group identities to endure within a legal framework upholding the rights and obligations of citizenship'.

Once more, the UK can serve as example of post-multiculturalist policies. P policy documents such as Improving opportunity, strengthening society (issued by the Home Office in 2005) show that the government is seeking simultaneously to be devoted to improving life chances and reducing inequalities among ethnic minorities (regarding education, jobs, health, housing and policing), promoting a cohesive society by bolstering a sense of common belonging and participation in civil society and fostering a greater understanding of the "range of cultures that contribute to our strength as a country". It seeks to better integrate immigrants through placing citizenship in school curricula, providing classes for immigrants on British history, customs and public services, stressing English language acquisition, providing citizenship tests, holding ceremonies for new citizens and possibly celebrating a Citizenship Day.

\section{Conclusion}

In diverse contexts around the world where some form of multiculturalism has obtained over the past two or three decades there are observers who put the blame for the supposed failure of integration directly on multicultural policies and ethnic minorities' persistent cultural practices and homeland orientations. They argue that too much cultural preservation and too many links maintained to places of origin are responsible for the poor conditions surrounding immigrants and their descendents. They suggest that the size and diversity of current migration patterns are leading to further social breakdown, particularly if supported by multicultural policies.

However multiculturalism has never been made up of a single type or piece of policy, institutional framework or programme. Moreover, most multicultural policies were intended not to produce economic outcomes or a sense of separateness among minority communities but rather a broad social acceptance and recognised inclusion in dominant public spheres.

Migration and cultural diversity will certainly remain high on the public agenda for many years to come. Meanwhile, patterns and processes of global migration are creating ever more contexts of super-diversity and migrants are maintaining 
strong diasporic identities and direct transnational ties with their homelands. The need for explicit policies and structures to engage with these issues is acute. If multiculturalism has been damaged surely something else must replace it.

Recent post-multicultural agendas certainly do not mean that multiculturalism is dead. It is just that the term or the "-ism" seems to be. No politician - except perhaps in Canada, where multiculturalism still enjoys prominence as part of the national identity - wants to be associated with the M-word. The gains of decades of multiculturalism, particularly a broad, everyday (or institutionally mainstreamed) acknowledgement of the gains and value of ethnic diversity, are still evident. This is to be seen in, among other sites, schools, organisations and workplaces. Further, in many places and despite anti-multicultural rhetoric, public opinion polls still tend to show high levels of respect for diversity. For instance, Eurobarometer recently noted that "Almost threequarters of EU citizens believe that people with a different background (ethnic, religious or national) enrich the cultural life of their country" (European Commission 2007, p.4).

Drawing upon the observations made above, the following post-multiculturalist recommendations can be offered (as indeed many were to the UK Commission on Integration and Cohesion and to UNESCO's recent World report on cultural diversity).

- While they point to important indicators of diversity, country of origin data may mask significant forms of differentiation. Within any particular group from a given country there will be important distinctions with reference to ethnicity, religious affiliation and practice, regional and local identities in places of origin, class and social status, kinship, clan or tribal affiliation, political parties and movements and other criteria of collective belonging. Surveys, policies and reports should take greater account of a range of variables when describing migrant or ethnic minority groups.

- Immigrants' channels of migration and the myriad legal statuses that arise from them are often just as crucial or even more important than shared ethnicity or country of origin with reference to how people group themselves and where they live, how long they can stay there, how much autonomy they have (versus control by an employer, for instance), whether their families can join them, what kind of livelihood they can undertake and maintain, and to what extent they can make use of public services and resources (including schools, health, training, benefits and other "recourse to public funds"). Immigration status is not just a crucial factor in determining an individual's relation to the state, its resources and legal system, the labour market and other structures; it is an important catalyst in the formation of social capital and a potential barrier to the formation of cross-cutting socioeconomic and ethnic ties. Legal status should be recognised more as a key variable of social differentiation.

- It is increasingly recognised that migrants engage in a variety of transnational practices such as sending remittances to their homelands. However, not all migrants maintain the same level or kinds of transnational engagement, socially, culturally, economically or politically. Much of this will be largely conditioned by a range of factors including their migration channel and legal status (e.g. refugees or people without documents may find it harder to maintain certain ties abroad), migration and settlement history, community structure and gendered patterns of contact, political circumstances in the homeland, economic means and more. Hence, transnational practices among immigrants are highly diverse between and within groups (whether defined by country of origin, ethnicity, immigration category or any other criteria). Policymakers should pay greater attention to such differentiation.

- Belonging, loyalty and sense of attachment are not parts of a zero-sum game based on a single nation-state or society. That is, it is not automatically true that the more transnational individuals are the less integrated they are, or that the less integrated they are the stronger their transnational patterns of association. While migrants continue to feel powerfully bound to homelands and communities elsewhere, they are now more able to maintain and enhance these feelings while at the same time being quite capable of developing a new life, livelihood, social ties and political interests in their places of settlement. Politicians, policy shapers, the media and other public actors should take these facts into account. 
- It is often clear in various studies that group interrelations are closely dependent on the existence or absence of competition for local resources and services (whether of the state, the voluntary or the public sector). Lack of conflict between ethnic groups is often due to the separation of communities into economic niches and differential demands on public resources. Policy-makers should reflect on whether their measures might actually make matters worse for minorities by creating the conditions for competition between them.

- In order to break down prejudices and encourage interaction, individuals should be made aware of each others' multiple category memberships in a way that promotes inclusiveness. People should be able to represent themselves by voicing their many identities, not simply a presumed ethnic one.

- Given the overwhelming fact that most new migrants move into places populated by previous cohorts of immigrants or ethnic minorities, a wide variety of interactions and integration processes occur among these groups - not just with regard to longstanding majority communities. Indeed, many immigrants often only meet, live in the same building with, socialise or work with other immigrants or ethnic minorities. These kinds of encounters and processes have hardly been addressed in social scientific research or policy development. Support should be given to previous migrant and ethnic minority groups in terms of assistance in integrating newcomers.

- Structures and modes of government support of and contact with ethnic minority organisations have for decades formed the core of models of multiculturalism. Especially on local levels, these have indeed often provided important forums for sharing experiences and needs, establishing good practices and providing access to services. However, in light of the numerous dimensions of contemporary super-diversity, such structures and modes are inadequate for effective representation. Most local authorities have been used to liaising with a limited number of large and well-organised associations; now there are far more numbers in smaller groups that are less organised (or not organised at all). Given new numbers and complexities of migration, just how many groups could such structures support? Existing minority ethnic agencies often cannot respond to the needs of the various newcomers. None of this is to say that community organisations no longer have a place in bridging migrant groups and local authorities or service providers. Such bodies remain crucial to the process, but they should be recognised as being only partially relevant with regard to their representativeness and scope.

- The growing complexity of the population carries with it a range of significant public service implications. Among these is a fundamental shift needed in strategies across a range of service sectors concerning the assessment of needs, planning, budgeting, commissioning of services, identification of partners for collaboration and gaining a broader appreciation of diverse experiences in order generally to inform debate. Such a shift must begin with gathering basic information on the new diversity. Existing measures are inadequate and may even impair service delivery. Moreover, no simple knowledge-based training in which service providers are taught the customs and values of particular ethnic minority cultures - can prepare professionals for all the issues that ever increasing diversity creates. Learning generic skills to respond flexibly to a wide range of cultural encounters is more appropriate.

- In order to avoid the conventional trap of addressing newcomers just in terms of some presumably fixed ethnic identity, an awareness of the new super-diversity suggests that policy-makers and practitioners should take account of new immigrants' plurality of affiliations (recognising multiple identifications and axes of differentiation, only some of which concern ethnicity). Recognition of the range of affiliations and engagements - such as affiliations with the localities in which they live- is likely to demonstrate that ethnic minorities are far better integrated than is often presumed.

It can be said that the turn from explicit multicultural discourse and policies has largely been based on a misreading of their purposes and effects (Vertovec and Wessendorf 2010). Nevertheless, the measures put in their place need not mean an emphasis on assimilation, or intolerance and a resurgence of jingoistic nationalism. Social cohesion and national identity can coexist with valuing diversity in the public sphere, as well as offering 
programmes to recognise and support cultural traditions, and institutional structures to provide ethnic minority community representation - all without reference to the M-word. In this way it is hoped that whatever a post-multicultural condition looks like, it might still entail the fashioning of a greater sense of cosmopolitanism, respect for others and social justice for migrants and their descendants.

\section{References}

Chicago Cultural Studies Group, 1994. Critical multiculturalism. In: D. T. Goldberg, ed. Multiculturalism: a critical reader. Oxford: Blackwell, 114-39.

Delanty, G., 2003. Community. London: Routledge.

Dustmann, C. and Fabbri, F., 2003. Language proficiency and labour market performance of immigrants in the UK. Economic Journal, Royal Economic Society, 113(489), 695-717.

European Commission, 2007. Third annual report on migration and integration. COM(2007)512 Final. Brussels: EC.

GiRoux, H. A., 1994. Insurgent multiculturalism and the promise of pedagogy. In: D. T. Goldberg, ed. Multiculturalism: a critical reader. Oxford: Blackwell, 325-43.

Glazer, N., 1997. We are all multiculturalists now. Cambridge, MA: Harvard University Press.

Hall, S., 2001. The multicultural question. Pavis Papers in Social and
Cultural Research no. 4. Milton Keynes: Open University.

KING, D., 2005. Facing the future: America's post-multiculturalist trajectory. Social Policy and Administration, 39 (2), 116-29.

MoraWsKa, E., 2003. Immigrant transnationalism and assimilation: a variety of combinations and the analytic strategy it suggests. In: C. Joppke and E. Morawska, eds. Toward assimilation and citizenship.

Basingstoke: Palgrave, 133-76.

Shohat, E. and Stam, R., 1994.

Unthinking Eurocentrism: multiculturalism and the media. New York: Routledge.

Sмiтн, R., 2006. Mexican New York: transnational lives of new immigrants. Berkeley, CA: University of California Press.

Snel, E., Engbersen, G. And Leekres, A., 2006. Transnational involvement and social integration. Global Networks, 6(3), 285-308.

Turner, T., 1993. Anthropology and multiculturalism: What is anthropology that multiculturalists should be mindful of it? Cultural Anthropology, 8, 411-29.

Vertovec, S., 1996. Multiculturalism, culturalism and public incorporation. Ethnic and Racial Studies, 19 (1), 49-69.

Vertovec, S., 1998.

Multimulticulturalisms. In: M. Martiniello, ed. Multicultural policies and the state. Utrecht: European Research Centre on Migration and Ethnic Relations, 25-38.

Vertovec, S., 2007. Super-diversity and its implications. Ethnic and Racial Studies, 29 (6), 1024-54.

Vertovec, S., 2009a. Conceiving and researching diversity. Go"ttingen: Max-Planck-Institute Working Paper WP 09-01.

Vertovec, S., 2009b.

Transnationalism. London: Routledge.

Vertovec, S. And Wessendorf, S., eds 2010. The multiculturalism backlash: European discourses, policies and practices. London: Routledge.

The Guardian, 2005. 21 January. 